\title{
Smart Technologies for Visually Impaired: Assisting and conquering infirmity of blind people using (AI) Technologies
}

\author{
Fatma Muhammad Salim Al- \\ Muqbali \\ Noura Abdullah Said Al-Tourshi \\ Khuloud Rashid Salim Al- \\ Kiyumi \\ Faizal Hajamohideen \\ College of Applied Science - Suhar \\ College of Applied Science - Suhar \\ College of Applied Science - Suhar \\ College of Applied Science - Suhar
}

\begin{abstract}
Physical disability has affected many people's lives across the world. One of these disabilities that strongly affected some large category of people is visual lose. Blind people often face difficulties in moving around freely such as: in crossing the street, in reading, driving or socializing. They often rely on using certain aid devices to reach certain places or perform any other daily activities such as walking sticks. There are ongoing scientific researches in the area of rectifying blindness, but it has to go long way to achieve the solution. Also, there are research unleashes the ideas of assisting the blind people deficiency but lacks in technological aspects of implementation. This research project aims at helping blind people of all categories to achieve their day to day tasks easier through the use of a smart device. By using artificial intelligent and image processing, this smart device is able to detect faces, colors and deferent objects. The detection process is manifested by notifying the visually impaired person through either a sound alert or vibration. Additionally, this study presents a palpable survey that entails visually impaired people from the local community. Subsequently, the project uses both Open CV and Python for programming and implementation. The exertion of this project prototype investigates the algorithms which are used for detecting the objects. Also, it demonstrates how this smart device could detects certain physical object and how it could send a warning signal when faced by any obstacles. Overall, this research will be a positive addition in the world of health care sector by supporting blind people with the use of smart technology
\end{abstract}

\section{Introduction:}

There are modern technologies that help people to practice their activities easily. We focused on the special needs categories which are blinds people. The third blind eye is a stick that makes blind people life easier. It helps them to walk and carry out their daily activities in an easy way and safety by using Internet of Things (IOT) and Artificial Intelligence (AI).

There are many researches underwent in Oman previously such as an engineering student at Dhofar University, has created a smart stick for the blind people. It is containing sensors, SIM card and GBS system. The SIM is very important for the blind people to communicate with their family and friends. Also, it is connected with a GPS that determines them location [1]. Ashraf Anwar1 and Sultan Aljahdalia from the Taif University. They are creating smart stick that is contains five sensors which are ultrasonic sensor, IR sensor, water sensor, fire sensor, and light (LDR) sensor. Also, it is connected with the GBS to know the direction for them [2]. Nadia Nowshin, Sakib Shadman, Saha Joy, Sarker Aninda and Islam Md Minhajul from American International UniversityBangladesh (AIUB). They are created stick for the blind people to detect the obstacles in the path they are use. The stick has Arduino Nano, HC SR-04 ultrasonic sensor, HC-05 Bluetooth module, push buttons, $100 \mathrm{nF}$ ceramic capacitors and a $9 \mathrm{~V}$ battery as the power source [3]. D.Siva kumar, 
M.Prem Anand, K.Deepan Raj, P.Thalapathi Raj, R.Yashwanth and S.Yogesh. They implemented technology stick for blind people that is contains Ultrasonic sensor to detect the obstacles in front of them, Ultrasonic sensor calculates the distance between the objects and the blind people, and Rf remote to help the blind people to find the location of the stick.

Also, some of countries use the face detection in security way. They use it to catch the thieves [4]. Bledsoe, Helen Chan and Charles Bisson, they are using the computer to recognize the face by using the computer in 1964 and 1965 [5, 6, 7, 8]. The lighting affects a lot in the color images to find the face, so they found the property of chrome, which adds good properties in the image [9]. They are tried to build face detection algorithm through face or skin color [10]. The stick contain sensor that provide distance between blind people and the objects by use Ultrasonic sensor, infrared (IR), Light dependent resistor (LDR) [11, 12, 13, 14].

Blind stick with Electronic Travel Aids (ETAs) with sensors and sound systems are designed to be easy for blind people for move and do daily activities [15], [16]. The blind people can move in easy way by use stick that contains ultrasonic sensors and mobile application [17]. In 2015 Agarwal and Kumar create stick that is contained ultrasonic sensor, GPS system and vibrating moto [18]. Stick uses a GPS receiver, vibrator and a headphone to navigate the blind person. Water sensor can detect water when level of the water is over $0.5 \mathrm{~cm}$. The object detection can determine only four type of object in front the blind if the objects are (concrete wall, human body, plastic \& cardboard box). An outdoor navigating device also came into attention in 2012[19]. The stick with sensor already exists for blind people but what makes our stick unique is using (Artificial Intelligence) AI. So, we use some programs like Python and Open Cv to detect and recognize faces, objects and colors. So, by this technology which helps to extract the face features the blind person will be able to know and understand the emotion and feeling of the person exist front of him. Also, with detecting colors he will be able to know if he is in the road or off the road.

In addition, our project will help him to know the exact objects around him by voice not like sensors which use vibration and cannot tells you the exact object front of them.

\section{Implementation Procedure}

In our project we use Python program and Opencv to implements the codes. And we used camera to tack images and detect faces, Ardiuno to download the programs and write the codes on it, Raspberry pi.

\section{Methodology}

As shown in the figure-1, we created dataset by gathering image of faces. Then we use the cascading algorithm for coding python program to capture faces images and store it in dataset folder. With the trained faces images to extract features we used another python program to recognize the faces exist in dataset folder. Finally, it code recognize people faces when the camera is focused any persons faces which stored in dataset the camera will recognize them and says the name by voice. 


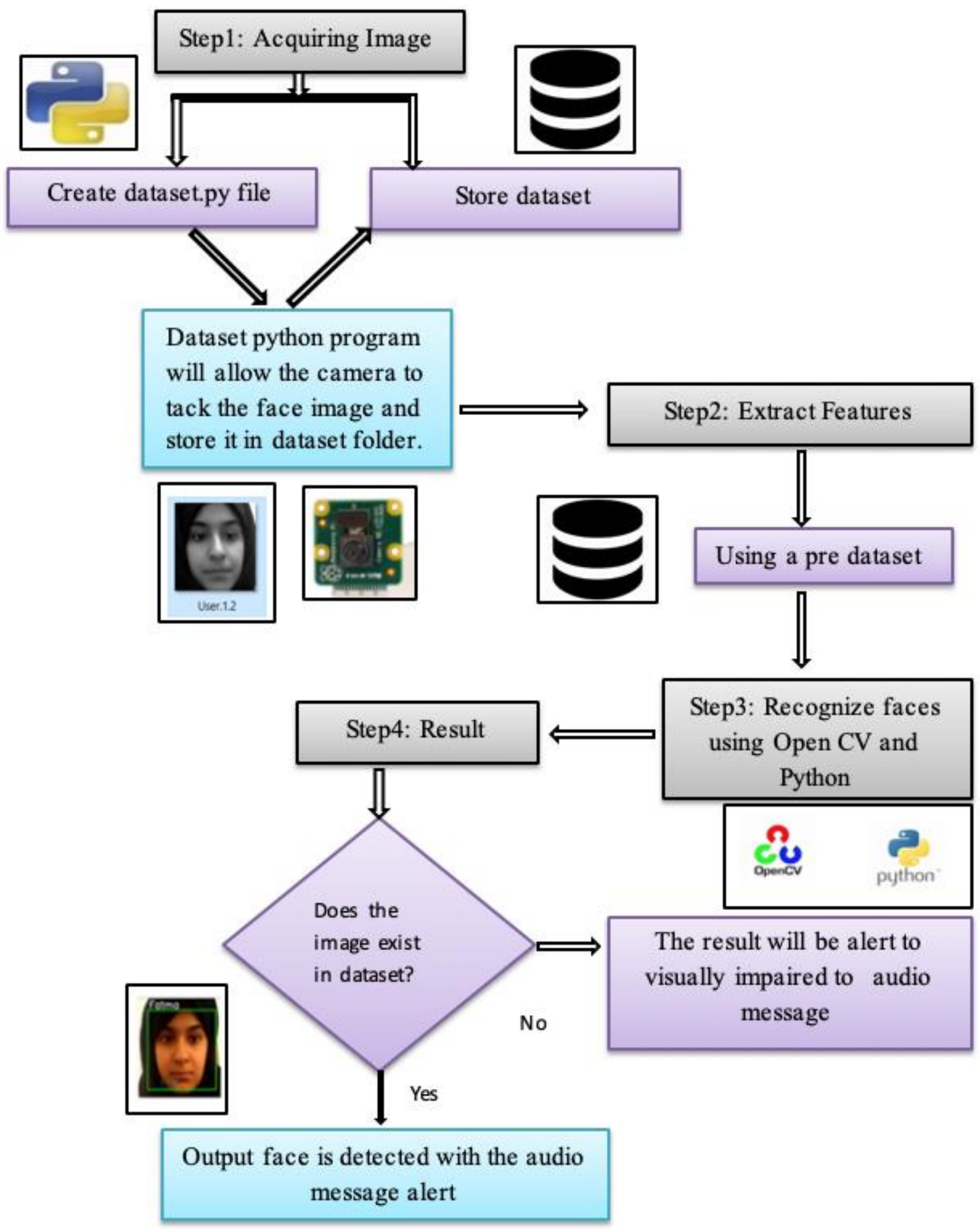

Figure 1. AI Based Smart System for Visually Impaired people.

\section{Experimental Scenario}


The experimental testbed is designed to adopt the finest algorithm which are then enabled to prepare coding as initiated in the methodology section. There are two algorithms Haar Cascade Algorithm and Local Binary Patterns Histograms(LBPH) are discussed and experimented in this research.

\section{Haar Cascade Algorithm:}

It is a machine learning object detection algorithm proposed by Paul Viola and Michael Jones in their 2001 paper entitled Rapid Object Detection using a Boosted Cascade of Simple Features as shown in the figure- 2

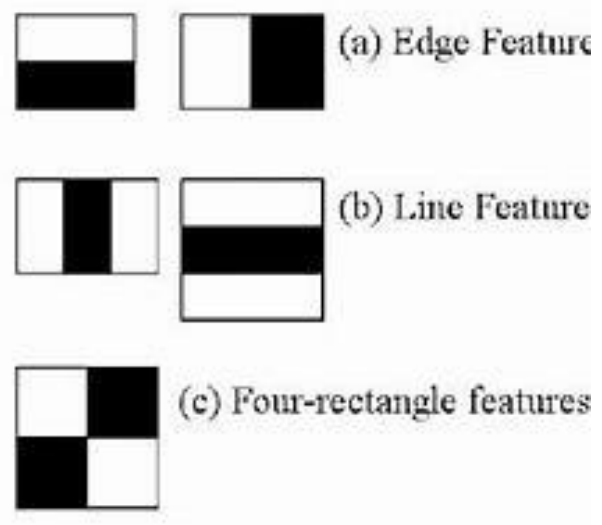

Figure 2. Haar Features

The figure 2 shows Haar algorithmic feature extraction methods and it's a digital imaging features used for object recognition.

1. Firstly, to train, we need lot of positive images and negative images are needed to train the classifier, these are images with faces and without faces.

2. Secondly, we need to extract features from images using a kind of 'filter' which are called Haar features shown in the figure 2.

3. The idea is to examine one part (or window) by passing these filters on the image

4. Then all the pixel intensities of the white and black portions are summed up for each window.

5. Ultimately, the value of the extracted feature is the value obtained by subtracting those two summations [20].

Figure 3. Extracted Features from the captured images

Haar Features moved within captured images to extract face's features the enables the image of the person is recognized is as shown in the figure 3

\section{LBPH Algorithm for face detection:}

Figure 4. Flow chart for LBPH Algorithm.

The LBPH algorithm of image processing used in this paper for optional trial mechanism for acquiring, detection, extraction and recognition as shown in the figure 4 . And the steps involve in 
the process of using LBPH algorithm as listed in the table 1.

\begin{tabular}{|l|l|}
\hline Step 1 & $\begin{array}{l}\text { LBPH (Local Binary Patterns Histograms), they have 4 } \\
\text { parameters Grid Y for vertical direction, Grid X for horizontal } \\
\text { direction, Neighbors and Radians. }\end{array}$ \\
\hline Step 2 & $\begin{array}{l}\text { Use a database containing the facial images with name so } \\
\text { same person's photos must have the same name as part of } \\
\text { training the algorithm }\end{array}$ \\
\hline Step 3 & $\begin{array}{l}\text { As part of applying the LBP operation: built image that } \\
\text { describe the original image be highlighting the } \\
\text { characteristics of the face by use radius and neighboring. }\end{array}$ \\
\hline Step 4 & $\begin{array}{l}\text { Use of Extracting Histograms: divide the image into multiple } \\
\text { grids using the Grid X and Grid Y. }\end{array}$ \\
\hline Step 5 & $\begin{array}{l}\text { At last, to perform the face recognition: Each histogram } \\
\text { created from the training dataset to represent each image. } \\
\text { Try this step for new image to compare the histogram for the } \\
\text { new image and training dataset. }\end{array}$ \\
\hline
\end{tabular}

Table 1. $L B P H$ algorithms implementation procedures

Figure 5. Python Open CV Code Haar Cascade Algorithm

Sample of Coding for Haar Cascade Algorithm to detect face and eyes are written in OpenCV and Python are shown in the figure 5.

Figure 6. Output of Hass Cascade algorithm.

The output of OpenCV and python program is depicted in the figure 6 . The output resulted with face detection with feature extractions are shown in different perspective such as the blue square and the eyes and nose are detected with green square.

\section{The result interpretations}

In our project we have developed the previous studies to be easier for the user by using artificial intelligence. The general idea in our project is to develop a stick for the blind people using the camera to recognize faces, colors and objects around them. Unlike previous studies, they use sensors in the stick to alert the blind people that an object is in front of them without recognizing the objects. In the stick that we are developed contains a camera to compares the image taken by the camera with the dataset. For example, we saved 30 pictures of a particular person and saved in the dataset, then the camera took a picture of that person and compares the image with dataset to know the name of the person, then the blind people get the result by a voice. In addition, the stick can recognize things like cars, bikes and animals. In addition, the stick can identify the colors, for example, when the color is black knows the blind people that it is in the street, but this depends on the location of the blind people, for example, if they in the house does not use color detection to know if they are in the street or not. We also added the help button, that used by the blind people when they are faced a problems or lose the road, this button works to send the location of the blind people to them family or friends to come to help them.

\section{Conclusion and Future Work}

The blind people who were deprived of the blessing of sight, have the right to live like normal people. Regardless of young people, they have lost their sense of sight. In our project, we studied to 


\section{Journal of Student Research}

Fourth Middle East College Student Research Conference, Muscat, Sultanate of Oman

innovate a smart stick for blind people and assist them to live in an easy way by using modern technology and artificial intelligence. We are surprised to learn many surveys done in this area. On the other hand, they have relied on the sensors in their projects, like the students of Dhofar University, Taif University and American International University the general idea is to use the ultrasonic sensor in the stick without specifying the type of object in front of them. We implement different techniques to implement the smart stick, specialty we benefited studying the use of artificial intelligence. Also, we learned to use python and Open cv to run the codes. we are implementing the camera in the stick to determine what is in front of the blind people and we add face detection, color detection with object detection. We studied two algorithms intensively as stated in the previous section such as Haar Cascade and LBPH algorithms.

This technique assures the blind people, now they know who is in front of them by using face detection, and what is kind of the object by using object detection. As part of our feature plan, we implement with the stick has a help button that the blind people use it when they are lost the route or faced some difficulties by sending the location to their family or friends by using SIM card. Additionally, in the future development, we are planning to implement the cognitive behavior of a person in front of the blind that can be detected by the camera, facilitating recording creating faces in the dataset by the blind himself. The Braille keyboard can be used to enhance the use of stick as part of this project will be implemented in the future.

\section{Reference:}

1. Al Shehri, N. Dhofar University student creates 'smart stick' for visually impaired. Available online: https://timesofoman.com/article/131848/Oman/Dhofar-University-student-createssmart-stick-for-visually-impaired (accessed on April 9, 2018).

2. Anwar, A, Aljahdali, S. A Smart Stick for Assisting Blind People. Available online: https://pdfs.semanticscholar.org/df35/9ab8b894f5180e844a1ff24f186c7ed75a67.pdf (accessed on May.-June. 2017).

3. Salton, k. A Smart Stick for Assisting Blind People. Available online: https://towardsdatascience.com/face-recognition-how-lbph-works-90ec258c3d6b (accessed on Nov 11, 2017).

4. W. W. Bledsoe. The model method in facial recognition. Technical report pri 15, Panoramic Research, Inc., Palo Alto, California, 1964.

5. W. W. Bledsoe. Man-machine facial recognition: Report on a large- scale experiment. Technical report pri 22, Panoramic Research, Inc., Palo Alto, California, 1966.

6. W. W. Bledsoe. Some results on multicategory patten recognition. Journal of the Association for Computing Machinery, 13(2):304-316, 1966.

7. W. W. Bledsoe. Semiautomatic facial recognition. Technical report sri project 6693, Stanford Research Institute, Menlo Park, California, 1968.

8. W. W. Bledsoe and H. Chan. A man-machine facial recognition system- some preliminary results. Technical report pri 19a, Panoramic Re- search, Inc., Palo Alto, California, 1965.

9. M.-H. Yang, D. Kriegman, and N. Ahuja. Detecting faces in images: A survey. IEEE Transactions on Pattern Analysis and Machine Intel- ligence, 24(1):34-58, January 2002

10. S. K. Singh, D. S. Chauhan, M. Vatsa, and R. Singh. A robust skin color based face detection algorithm. Tamkang Journal of Science and Engineering, 6(4):227-234, 2003.

11. M.H.A. Wahab, A.A. Talib, et al., "Smart cane: Assistive cane for visually-impaired people," IJCSI International Journal of Computer Science Issues, vol. 8, no. 4, pp. 21-27, 2011.

12. S. Adhe, S. Kunthewad, P. Shinde and V.S. Kulkarni, "Ultrasonic smart stick for visually impaired people," IOSR Journal of Electronics and Communication Engineering, pp. 11-15, 2015. http://assistech.iitd.ernet.in/smartcane.php

13. M. Varghese, S.S. Manohar, et al., "The smart guide cane: An enhanced walking cane for assisting the visually challenged," in Proc. of the International Conference on Technologies for Sustainable Development, Mumbai, India, Feb 4-6, 2015.

14. A. Bhokare, A. Amberkar, A. Gawde, P. Kale, and A. Pasi, "Ultrasonic blind walking stick," 


\section{Journal of Student Research}

Fourth Middle East College Student Research Conference, Muscat, Sultanate of Oman

Int. J. on Recent and Innovation Trends in Computing and Comm., vol. 4, no. 1, pp. 62-65, 2016.

15. Rene Farcy, Roger Leroux, Alain Jucha, Ronald Damaschini, Colette Gregoire, Aziz Zogaghi

" Electronic Travel Aids And Electronic Orientation Aids For blind people: Technical,

Rehabilitation And Everyday Life Points Of View", Conference \& Workshop on Assistive Technologies for People with Vision \& Hearing Impairments Technology for Inclusion CVHI 2006.

16. Gayathri, G., Vishnupriya, M., Nandhini, R., and Banupriya, M. M.”SMART WALKING STICK FOR VISUALLY IMPAIRED." International Journal of Engineering and Computer Science, Vol.3, pp.4057-4061, 2014.

17. K. Chaitrali, D. Yogita, K. Snehal, D. Swati, and D. Aarti, "An intelligent walking stick for the blind," International Journal of Engineering Research and General Science, vol. 3, Issue1, November, 2016.

18. Ankit Agarwal, Deepak Kumar, Abhishek Bhardwaj "Ultrasonic Stick for Blind," International Journal of Engineering and Computer Science, vol. 4, Issue 4, April, 2015.

19. Anon, n.d. Electronic Walking Stick for the Blind, s. 1.:s.n.

20. Alto, V. Face recognition with OpenCV: Haar Cascade. Available online: https://medium.com/dataseries/face-recognition-with-opencv-haar-cascade-a289b6ff042a. (accessed on Jul 16, 2018). 